\title{
Two-Phase Treatment of a Growing Patient with a Skeletal Class II
}

\author{
Manish Suresh Sonawane, Girish Ramchandra Karandikar, Shashank Sharad Gaikwad \\ Priyanka Anil Pawar, Shaili Sanjay Shah
}

\begin{abstract}
Functional appliances have been used for many years in the treatment of class II malocclusions. They redirect the growth of mandible bringing about a skeletal change in a growing patient. In case of any remaining dental discrepancy, a fixed appliance is obligatory. This patient was an 11-year-old growing female with a convex profile, receding chin, lower lip trap, class II skeletal and dental relationship, a large overjet and overbite and a high maxillary labial frenum attachment. Treatment started with the Twin-block appliance with an expansion screw to achieve transverse correction, promote growth of the mandible and improve her profile. This was followed by fixed appliance mechanotherapy to align and level the dentition, close spaces and retract the maxillary anteriors. Frenectomy was carried out after space closure.
\end{abstract}

Keywords: Skeletal class II, Growing patient, Two phase treatment, Twin-block appliance, Functional appliance.

How to cite this article: Sonawane MS, Karandikar GR, Gaikwad SS, Pawar PA, Shah SS. Two-Phase Treatment of a Growing Patient with a Skeletal Class II. J Contemp Dent 2013;3(1):40-43.

\section{Source of support: Nil}

Conflict of interest: None declared

\section{INTRODUCTION}

Sagittal and transverse discrepancies often coexist in skeletal class II malocclusions. ${ }^{1-3}$ Orthopedic growth modification can work well in such cases provided that the remaining pubertal growth is adequate and that the clinician can time the treatment to coincide with the peak growth period. ${ }^{4,5}$ The transverse discrepancy is generally corrected first, establishing a proper base for the sagittal correction to follow. ${ }^{6,7}$ For example, in a skeletal class II case with a narrow maxillary arch and retrusive mandible, maxillary expansion is performed initially/concurrently to facilitate functional mandibular advancement. ${ }^{8}$

Functional appliances cause alteration of maxillary growth, improvement in mandibular growth and position, and change in dental and muscular relationships. ${ }^{9}$ The twinblock appliance, originally developed by William Clark, ${ }^{10}$ is a widely used functional appliance for the management of class II malocclusion. The appliance can be worn almost full-time. It has the advantage of allowing nearly a full range of mandibular movement. The patients get acclimatized to wearing it very easily. Normal speech is far easier to achieve in the shortest possible time with this appliance. Thus, its popularity comes from its high patient acceptability and a concurrent ability to produce rapid results.

In a two-stage treatment, the functional phase involves the use of the twin block appliance (removable/fixed variety) to reposition the mandible forward until the overjet and overbite are corrected. ${ }^{11}$ When that occurs, the permanent molars will be in contact and the maxillary and mandibular incisors will be nicely coupled but the intervening teeth may not necessarily be in occlusion. ${ }^{12}$ To ensure that the patient does not have a dual bite, the appliance is worn fulltime for a minimum period of 7 to 9 months. After this functional appliance phase is completed, for accurate individual positioning of teeth in three planes of space, fixed orthodontic treatment is usually necessary for the settling of occlusion and maintenance of the skeletal correction achieved and correction of any remaining dental discrepancy.

\section{CASE REPORT}

An 11-year-old prepubertal female presented with the chief complaint of forwardly placed and spacing with respect to upper front teeth. She exhibited a convex profile, an obtuse nasolabial angle, incompetent lips, a protrusive upper lip, a trapped lower lip and a deficient chin.

Intraoral findings show a permanent dentition, class II incisor and molar relationships, end-on cuspid relationship bilaterally and a constricted maxillary arch. The maxillary anterior teeth were severely proclined and forwardly placed, with increased overjet and overbite (10 and $6 \mathrm{~mm}$ respectively) and traumatic anterior bite. The maximum protrusive was $11 \mathrm{~mm}$. Midlines were coincident and she displayed a high maxillary labial frenum attachment.

\section{DIAGNOSIS}

Cephalometric analysis confirmed the diagnosis of a class II, division 1 malocclusion on a skeletal class II base, with an average growth pattern and a marked mandibular retrusion. Evaluation of the patient's cervical vertebrae maturity indicators (CVMI) indicated she was in the acceleration phase of growth, with considerable (75\%) growth remaining (Fig. 1).

\section{TREATMENT PLAN}

The pubertal growth status of a patient is more critical for sagittal correction and because the patient was approaching 
the peak of pubertal growth, we decided to institute the first phase of treatment by carrying out the sagittal correction along with transverse correction with a functional orthopedic approach. A removable twin block appliance with an expansion screw was chosen to expand the maxillary arch and stimulate the forward mandibular growth. This was to be followed by second phase of treatment with fixedappliance therapy for space closure, retraction of the anterior teeth and finishing and detailing of the occlusion. Frenectomy was to be carried out after space closure (Fig. 2).

\section{TREATMENT PROGRESS}

The twin block appliance was fabricated with a $7 \mathrm{~mm}$ single step sagittal advancement and a $5 \mathrm{~mm}$ vertical opening in the premolar region. The patient was instructed to wear the appliance full-time except contact sports. The expansion screw was activated by the patient by one quarter turn twice weekly for 6 weeks (Fig. 3).

After 10 months of good compliance, the patient showed a super class I molar relationship without a dual bite and a considerably improved facial profile. At the end of this phase of treatment, the patient now presented a class I molar and cuspid relationship, an overjet and overbite of $4 \mathrm{~mm}$. The increased arch width in the cuspid region had removed the occlusal interferences and settled the canines into a class I relationship.

Phase II treatment with a preadjusted edgewise appliance (PEA) was now initiated with McLaughlin Bennet Trevisi
(MBT) prescription 0.022" brackets being then direct bonded. Leveling and aligning was done using round $0.016^{\prime \prime}$ nickel-titanium (NiTi), followed by round $0.018^{\prime \prime}$ stainless steel wire. A diamond plasty type of frenectomy was then carried out in the Department of Periodontology of our institution. A retraction utility arch was placed to intrude and retract the maxillary anterior teeth, thus effecting closure of the anterior spacing.

The patient is currently at this stage of treatment with an overjet and overbite of $2 \mathrm{~mm}$. The molar, cuspid as well as incisor relationship is class I. All that now remains is achieving proper incisor torque during the finishing and detailing of the occlusion to bring the case to a finish (Fig. 4).

\section{DISCUSSION}

There are obvious advantages of treating class II patients with a removable functional appliance prior to fixed appliance therapy. Management of distal occlusion with functional appliances can lead to improvement in orofacial function through better muscle adaptation concurrent to the dental and skeletal changes achieved. ${ }^{13}$ Ideal timing for orthopedic treatment for mandibular deficiency is after onset of pubertal growth spurt. ${ }^{14}$

Though it is argued by some that the orthopedic phase and orthodontic treatment phase should be combined in one single treatment, ${ }^{15-17}$ the positive effect on improved selfesteem of the patient as well as a concurrent reduction in
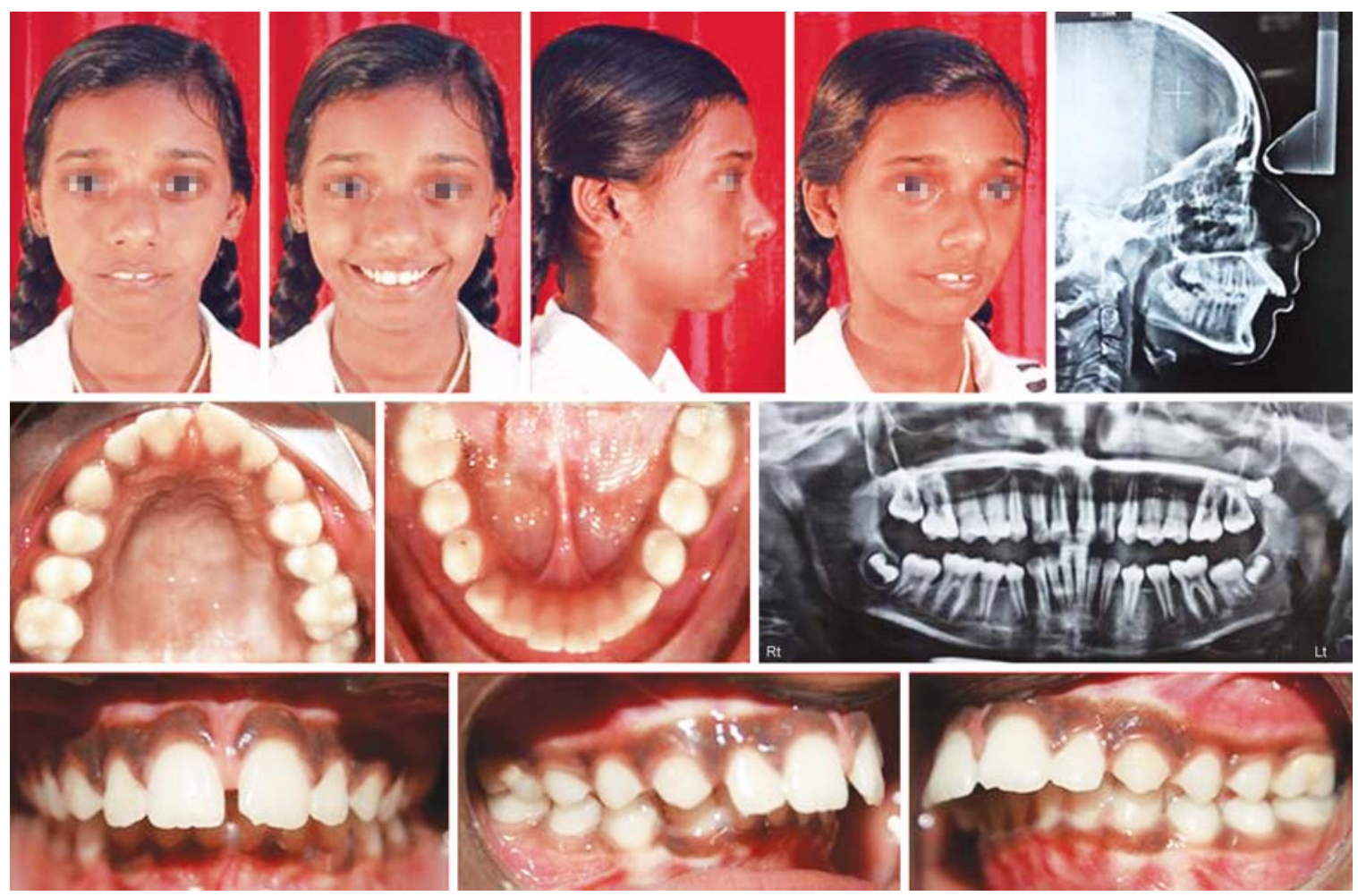

Fig. 1: Pretreatment records 
the accident-proneness for procumbent incisors outweighs the aforesaid. ${ }^{18}$

Since the patient had a skeletal class II pattern with a retrognathic mandible at the preadolescent stage (as indicated by CVMI), it was necessary to use a functional appliance to correct the skeletal anteroposterior and transverse discrepancies. Early intervention by functional appliances resulted in using this growth potential to attain the obtained results, improved self-esteem. ${ }^{11-14}$

Success with this treatment result depends upon slight overcorrection of the buccal segments (molars and canines) to a super class I, which builds anchorage into the system prior to placement of the fixed appliances and allows for a slight rebound.

\section{SUMMARY}

The advantages offered by a two-phase correction of skeletal class II presented in a growing patient have been discussed. The case outlined is perfect representation of the type that would benefit optimally with such an approach. The allround improvement in having achieved a better soft tissue balance, a near perfect occlusion and imparting a positive personality change with a concurrent improved self-esteem have underlined the merits of this approach.

\section{CONCLUSION}

The advantages of the two-phase treatment approach have been made evident and in the opinion of the authors are useful tools in the armamentarium of the clinician.
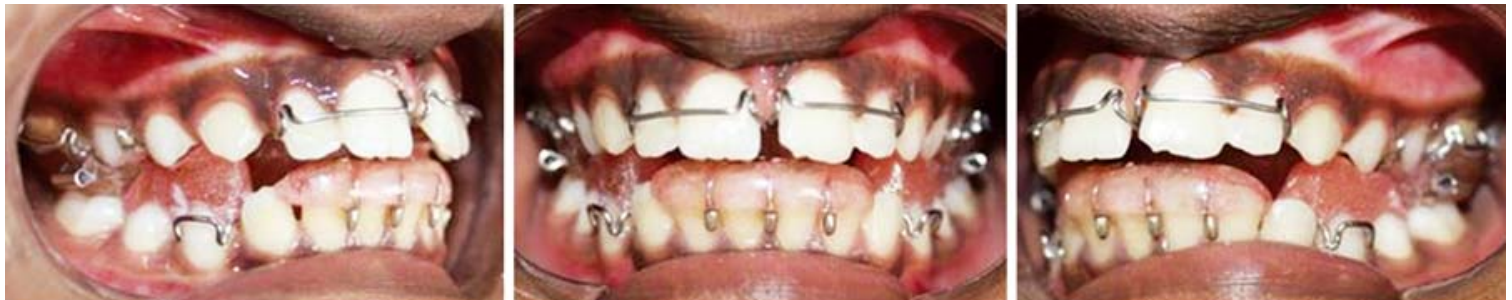

Fig. 2: Intraoral photographs with twin blocks in place
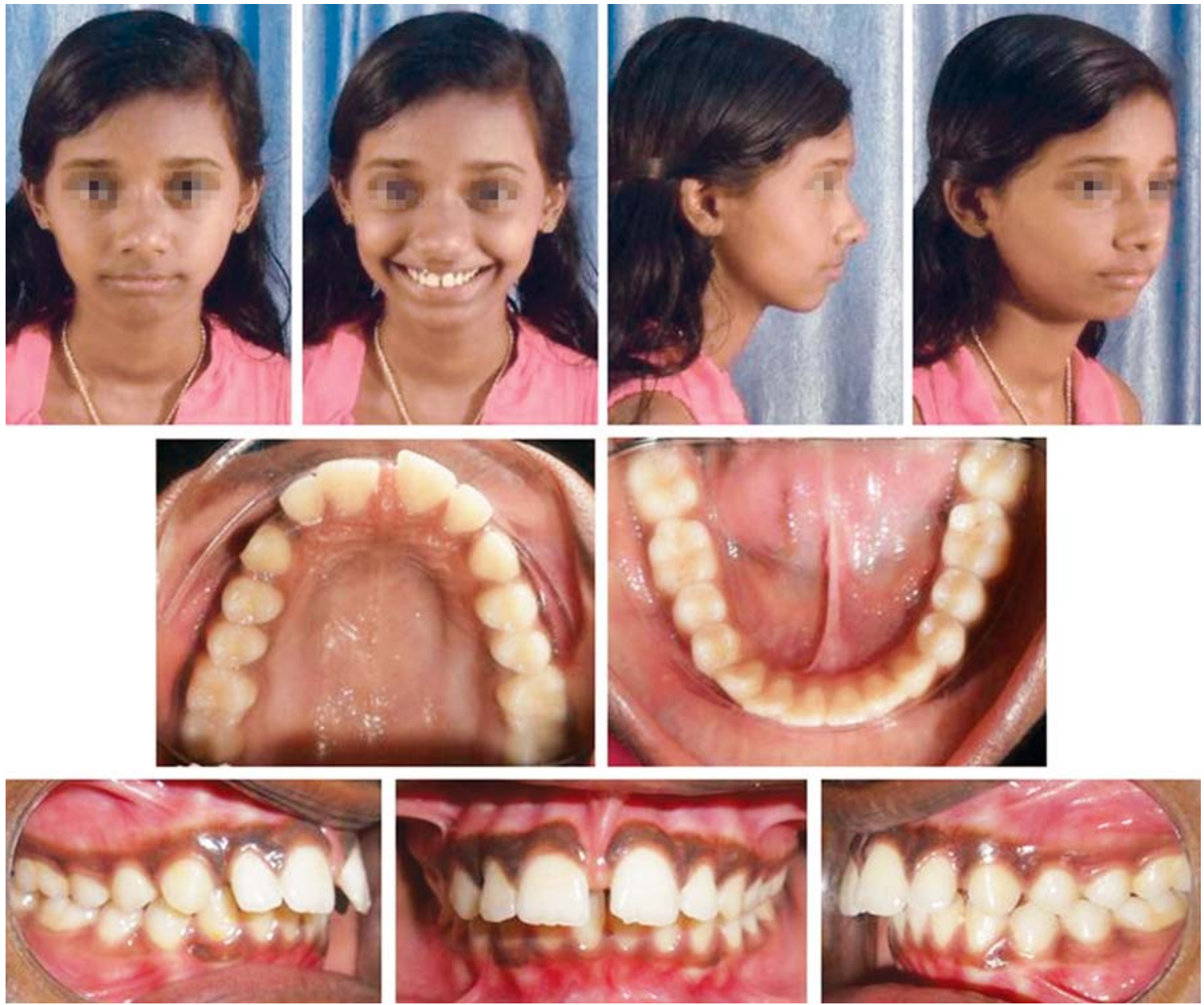

Fig. 3: End of phase I (postfunctional appliance therapy) 

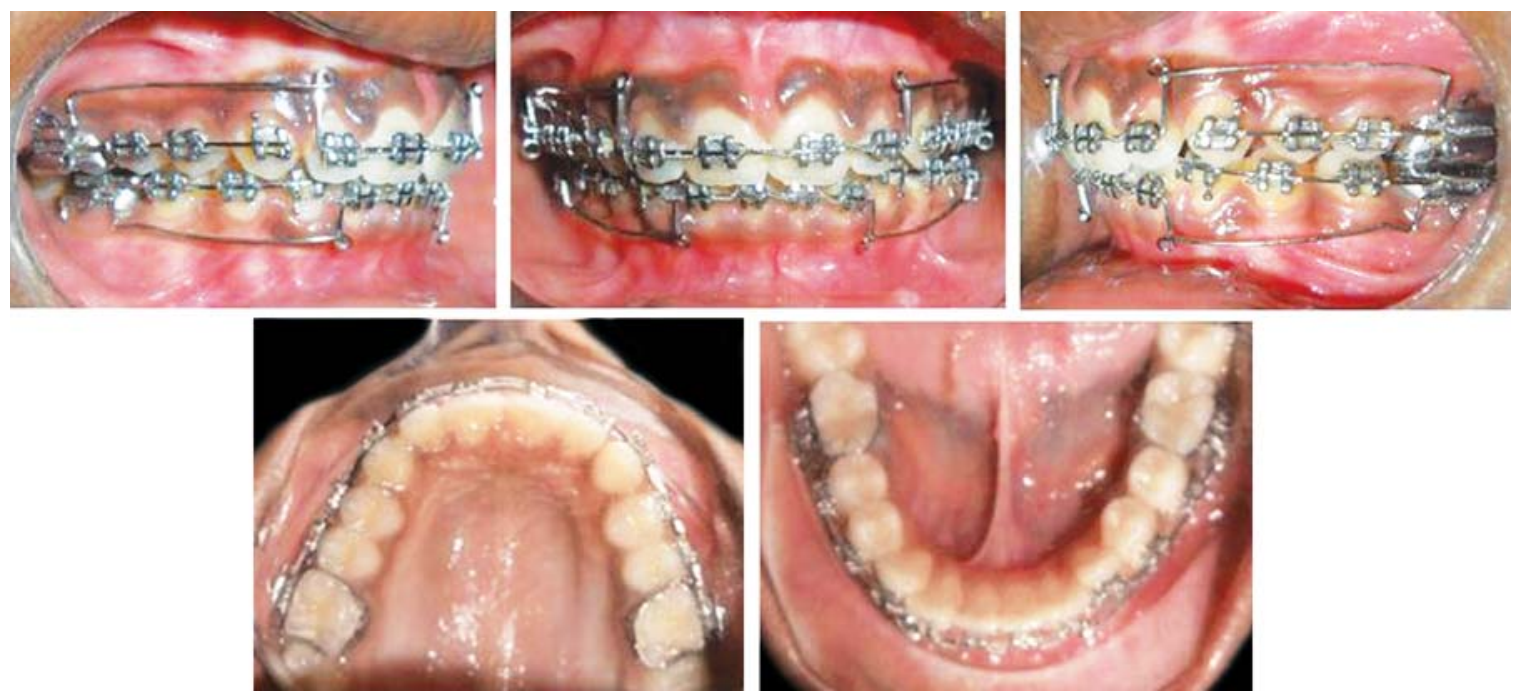

Fig. 4: Fixed appliance with upper and lower utility arches

\section{REFERENCES}

1. Staley RN, Stumtz WR, Peterson LC. A comparison of arch width in adults with normal occlusion and adults with class II. Division I malocclusion. Am J Orthod 1985;88:163-69.

2. Tollaro L, Baccetti T, Franchi L, Tanasescu CD. Role of posterior transverse interarch discrepancy in class II. Division l malocclusion during the mixed dentition phase. Am J Orthod 1996;110:417-22.

3. Bacceti T, Franchi L, McNamara JA, Tollaro I. Early dentofacial features of class II malocclusion. Am J Orthod 1997;111:502-09.

4. Pancherz H, Hgg U. Dentofacial orhtopaedies in relation to somatic maturation. Am J Orthod 1985;88:273-87.

5. Hagg U, Pancherz H. Dentotacial orhtopaedics in relation to chronological age. Growth period and skeletal development: An analysis of 72 male patients with class II Division I malocclusion treated with the Herbst appliance. Eur J Orthod 1988;10:169-76.

6. McNamara JA Jr, Brudon WL. Orthodontics and orthopedic treatment in the mixed dentition. Ann Arbor Needham Press 1993;85-88.

7. McNamara JA Jr, Peterson JE Jr, Alexander RG. Threedimensional diagnosis and management of class II malocclusion in the mixed dentition. Semin Orthod 1996;2:114-37.

8. Kingsley NW. A treatise on oral deformities as a branch of mechanical surgery. London HK Lewis 1880;124.

9. Jena AK, Duggal R, Parkash H. Skeletal and dentoalveolar effects of twin-block and bionator appliances in the treatment of class II malocclusion: A comparative study. Am J Orthod Dentofacial Orthop 2006;130:594-602.

10. Clark WJ. The twin block traction technique. Eur J Orthod 1982;4:129-38.

11. Dyer FMV, McKeown HF, Sandler PJ. The modified twin block appliance in the treatment of class II Division 2 malocclusions. J Orthodont 2001;28(4):271-80.

12. Mills CM, Ma Culloch KJ. Treatment effects of twin block appliance: A cephalometric study. Am J Orthod Dentofacial Orthopaed 1998;114:15-24.

13. Harzer, et al. Molecular diagnosis in Orthodontics, Facialorthopedics and orthognathic surgery: Implications for treatmentprogress and relapse. Semin Ortho 2010;16:118-27.

14. McNamara, et al. Treatment timing for twin-block therapy. Am J Orthod Dentofacial Orthop 2000;118:159-70.
15. Tulloch C, Profitt WR, Phillips C. Outcomes in a 2-phase randomized clinical trial of early class II treatment. Am J Orthod Dentofacial Orthop 2004;125:657-67.

16. McGorray, King B. Wheeler timing of class II treatment: Skeletal changes comparing 1-phase and 2-phase treatment. Am J Orthod Dentofacial Orthop 2007;132:481-89.

17. O’Brien K, et al. Early treatment for class II Division 1 malocclusion with the twin-block appliance: A multi-center, randomized, controlled trial. Am J Orthod Dentofacial Orthop 2009;135:573-79.

18. O’ Brien K, et al. Effectiveness of early orthodontic treatment with the twin-block appliance: A multicenter, randomized, controlled trial. Part 2: Psychosocial effect. Am J Orthod Dentofacial Orthop 2003;124:488-89.

\section{ABOUT THE AUTHORS}

\section{Manish Suresh Sonawane (Corresponding Author)}

Lecturer, Department of Orthodontics, Mahatma Gandhi Mission's Dental College and Hospital, Navi Mumbai, Maharashtra, India e-mail: dr.manish94@yahoo.com

\section{Girish Ramchandra Karandikar}

Professor and Head, Department of Orthodontics, Mahatma Gandhi Mission's Dental College and Hospital, Navi Mumbai, Maharashtra, India

\section{Shashank Sharad Gaikwad}

Senior Lecturer, Department of Orthodontics, Mahatma Gandhi Mission's Dental College and Hospital, Navi Mumbai, Maharashtra, India

\section{Priyanka Anil Pawar}

Postgraduate Student, Department of Orthodontics, Mahatma Gandhi Mission's Dental College and Hospital, Navi Mumbai, Maharashtra, India

\section{Shaili Sanjay Shah}

Postgraduate Student, Department of Orthodontics, Mahatma Gandhi Mission’s Dental College and Hospital, Navi Mumbai, Maharashtra, India 